\section{KEEP YOUR PATIENTS SAFE}

Tooth whitening is the most popular cosmetic dentistry procedure in the UK.

However, as the headlines and news warn, there are an array of hoaxers and risky, often dangerous products available that could lead to tooth enamel destruction, blisters, irritation and sensitive gums.

By providing UK-manufactured, Professional Tooth Whitening Kits from Sparkle Dental Labs at your surgery you can build trust and confidence and ensure that patients safely receive the treatment they want. After a professional consultation patients can receive a customised tooth whitening kit to meet a variety of needs and colour shades. Sparkle Dental Labs tooth whitening kits are available in varying strengths (6\% HP, 16\% CP or 10\% $\mathrm{CP})$ and are created with a unique formula to reduce dehydration and sensitivity.

As all kits have been developed by experts and manufactured in the UK, every material used is traceable, making Sparkle Dental Labs tooth whitening kits one of the safest ways for patients to achieve the results they desire.

Don't let your patients run the risk of damaging their teeth by contacting Sparkle Dental Labs now.

For more details about Sparkle Dental Labs, call 0800138 6255, email customerservice@sparkledentallabs.com or visit www.sparkledentallabs.com.

\section{MAKING BRUSHING CHILD'S PLAY}

Philips innovative Sonicare for Kids sonic toothbrush is aimed at children between the ages of 4 and 10 . The kid-friendly power toothbrush is designed to help children develop effective brushing habits early, for a lifetime of good oral health.

The recently upgraded Sonicare for Kids comes with a selection of eight funky designs for its interchangeable decorative front panels which can be peeled on and off to suit the child's whims. The packaging features the Sonicare for Kids swathed in a red cape, underlining its super-hero credentials.

However, the brush is not just eye-catching; studies amongst children in the target age group shows that Phillips Sonicare for Kids removes significantly more plaque than a children's manual toothbrush - up to $75 \%$ more in hard-toreach areas.

Sonicare for Kids features two intensity settings including a sensitive mode which is gentle on developing teeth and gums to help kids make the transition from a manual to an electric toothbrush. It also features two different sized brush heads to accommodate growing mouths, as well as the option of a sensitive brush head.

The advantages of Sonicare for Kids from the dental professional's perspective are manifold. First and foremost, they can advise parents of their young patients to use Sonicare technology because it is clinically proven to achieve better oral health results in children. The kid-friendly features are designed to increase compliance for better long-term brushing habits, plus clever ergonomics help kids handle the toothbrush more effectively and make it less technique sensitive to encourage better brushing results.

More information can also be obtained by visiting www.sonicare.com, calling 08000567222 or visiting Philips' stand K115 at BDIA Dental Showcase.
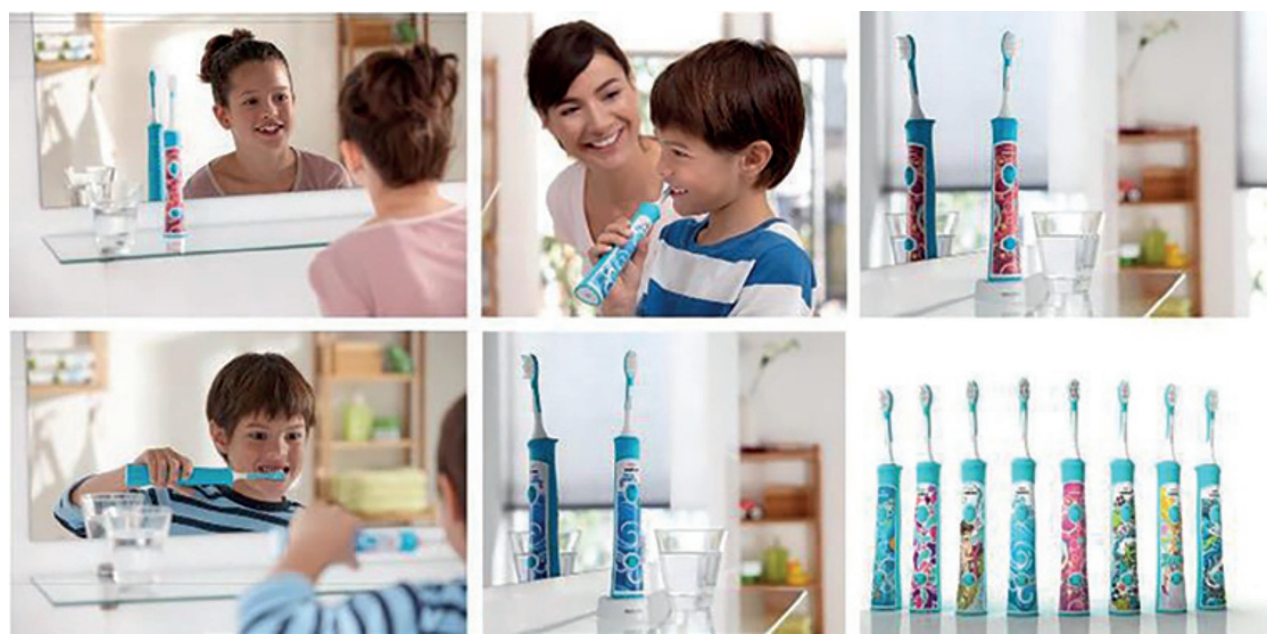

\section{INCORPORATION LATEST}

The issue of incorporation for dentists has become more complex following both the 2014 Autumn Statement and the 2015 Budget. Alan Suggett is a specialist dental accountant and a member of the NASDAL technical committee and believes incorporation can still be advantageous for some dentists.

He explains how the potential tax benefits of incorporation have been impacted:

- Full CGT (28\%) payable at sale of goodwill to the limited company (rather than 10\% under Entrepreneurs Relief)

- Abolition of Corporation Tax Relief on 'amortisation' of goodwill in the limited company. This effectively means additional tax payable of $20 \%$ of the goodwill value

- Abolition of the tax credit on dividends. This leads to an extra income tax charge of 7.5\% on dividend income taken from limited companies (other than the first $£ 5,000$ ).

As a consequence, he says, various planning schemes have been devised, but not all are practical and depending on individual circumstances, might be inadvisable. Advice from a specialist dental accountant and lawyer is essential.

To contact Alan, email alansuggett@unw.co.uk or to find out more about NASDAL, go to www. nasdal.org.uk

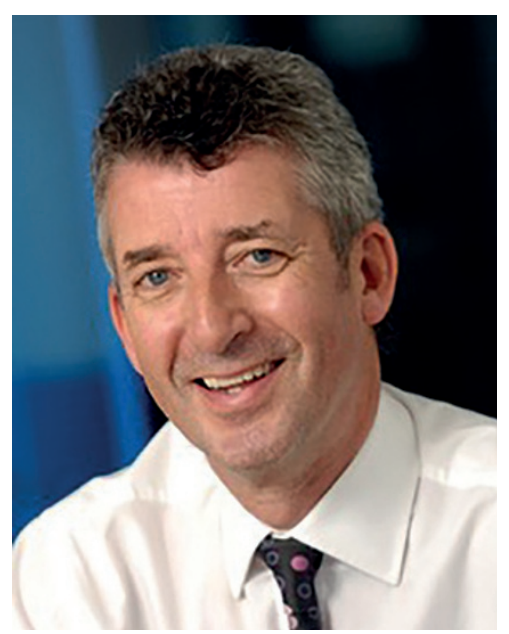

